\title{
Combined Coal Pyrolysis and Combustion Poly- Generation System Based on Fluidized Bed
}

\author{
Cen J, Fang $\mathbf{M}^{*}$, Wang QZL and Cen $\mathrm{K}$ \\ State Key Laboratory on Clean Energy Utilization, Zhejiang University, China
}

Submission: July 20, 2017; Published: August 04, 2017

*Corresponding author: Fang M, State Key Laboratory on Clean Energy Utilization, Zhejiang University, 310027, Hangzhou, China, Email: mxfang@ zju.edu.cn

\begin{abstract}
A new coal pyrolysis and combustion poly-generation system combined coal combustion and pyrolysis has been developed for clean and high efficient utilization of coal. Coal is first pyrolysedin a fluidized bed pyrolyzer. The

pyrolysis gas is then purified and used for chemical product or liquid fuel production. Tar is collected during purification and can be processed to extract high value product and to make liquid fuels by hydro-refining. Semi-coke from the pyrolyzer is burned in a circulating fluidized bed (CFB) combustor for heat or power generation. The system can realize coal multi-product generation and has a great potential to increase coal utilization value. The application prospect of the new system was discussed.
\end{abstract}

Keywords: Poly-generation; Coal pyrolysis; Tar utilization; Combustion; Gas conversion

\section{Introduction}

The conventional coal conversion technologies, such as liquefaction, gasification, combustion and carbonization, had been developed, and so far, the coal was utilized widely not only as the power energy, but also as resources to produce the chemical liquids and gas fuels, whereas the coal extensive utilization induced a large quantity of serious effects on environment. The poly-generation was an integrated utilization approach to realize the maximum adding-value to coal. A number of researchers devoted their focus on polygeneration based on the coal pyrolysis.

Nigel Paterson [1] developed the air-blown gasification cycle (ABGC) and investigated the flexibility of the reaction process in the pressured pilot-scale reactor. Yunhua Zhu et al. [2]. Studied the performance behaviors of coal-to-fuel poly-generation systems of coal-to-FT oil and coal-to-SNG, and the results demonstrated the coal-to-SNG process owned higher energy and energy efficiencies due to its low power consumption and less heat loss for product cooling. Qun Yi et al. [3] proposed a new optimized method for integrated poly-generation system and investigated the effect of key operating conditions on the chemical conversion and energy utilization process of the whole system. Paolo Chiesa et al.
$[4,5]$ investigated performances, costs and prospects of polygeneration system which converted coal to hydrogen and electricity with carbon dioxide capture and storage. Through this system the effects of changing the ratio of electricity/ $\mathrm{H}_{2}$, gasifier pressure and purity of hydrogen were explored. By integrating a circulation fluidized bed (CFB) boiler and a fluidized bed pyrolyzer into one system, a new coal polygeneration system was developed in this paper. Coal will be pyrolyzed in the pyrolyzer first. Hydrogen-rich components were converted into gas and tar, and the remaining semi-coke burned in a combustor for heating and power generation. Thus, poly-generation of gas, tar, heat and power can be realized in one system.

Coal Pyrolysis and Combustion Poly-Generation System

To realize comprehensive utilization of coal, a new pyrolysis and combustion poly-generation system combined coal combustion and pyrolysis has been put forward which combines a circulating fluidized bed boiler and a fluidized bed pyrolyzer to realize coal pyrolysis and combustion in one system (Figure 1). Here are the processes. First coal is fed into a pyrolyzer to be heated and pyrolyzed. Pyrolysis gas is then 
cooled and purified and used for chemical product or liquid fuel production. Tar is collected during purification and can be processed to extract monocyclic aromatic hydrocarbons and polycyclic aromatic hydrocarbons (PAHs) etc and to make liquid fuels by hydro-refining. The heat absorbed in the pyrolyzer is supplied by high temperature circulating solids from a CFB boiler furnace. Semi coke produced in the pyrolyzer is transported into the CFB boiler furnace with circulating solids to burn out, and to produce steam. Steam can be used to generate electricity, supply heat, etc. The system has following advantages:

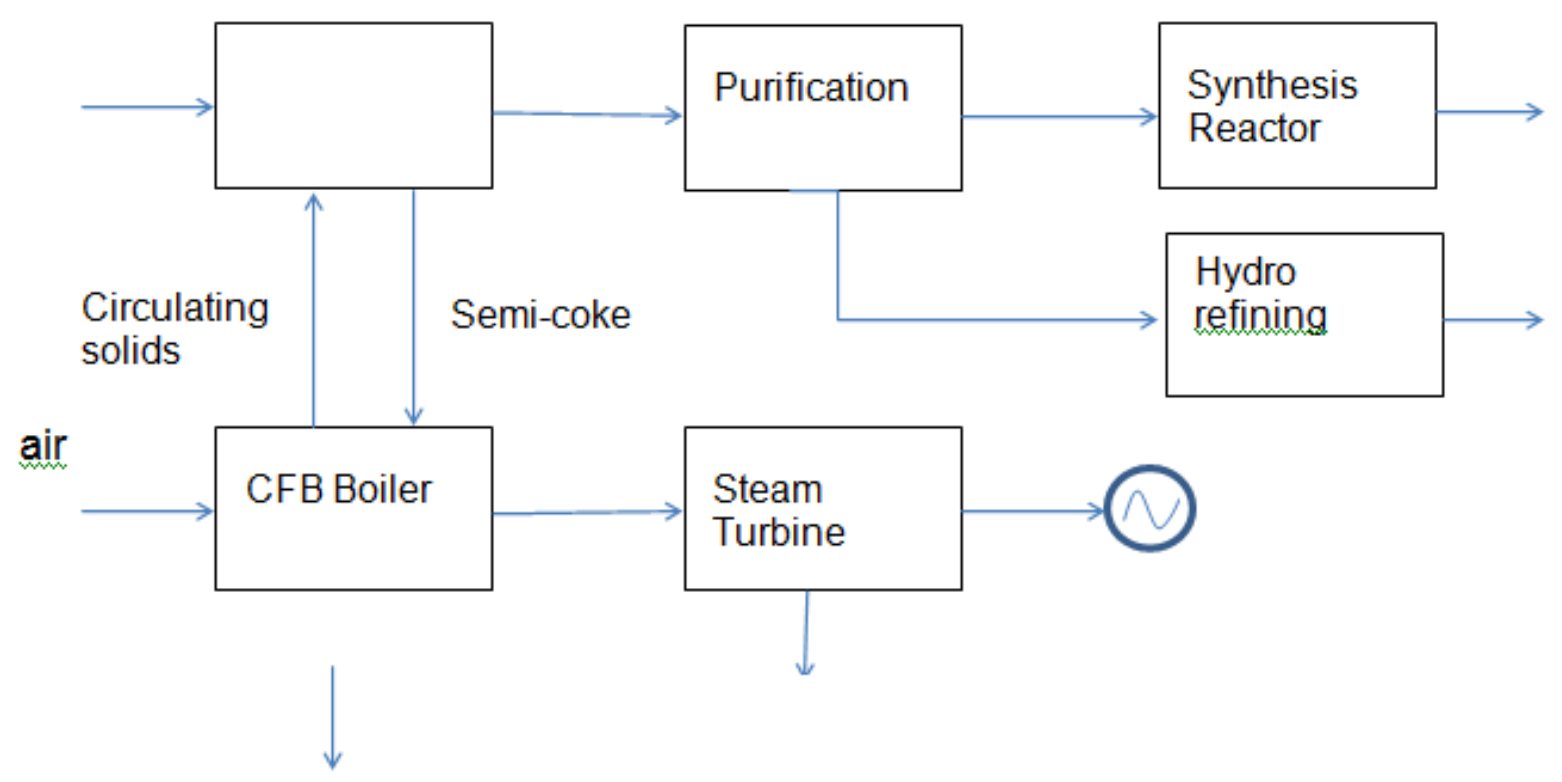

Figure 1: Coal pyrolysis and combustion poly-generation system combined combustion and pyrolysis.

a) It produces not only power, but also tar and gas, which can be converted as chemicals, liquid fuels, city gas or syngas, etc. So it provides a promising alternative energy.

b) Good fuel adaptability. Most bituminous coal and lignite coal can be used for the system.

c) Using pyrolysis and combustion technology, valuable fractions of coal, such as the volatile fraction, are extracted and semi coke is burned at boiler. Coal composition is fully utilized.

d) Most of sulfur compounds, nitrogen bases, and undesirable pollutant are removed during the pyrolysis.

Therefore, pollutant emission from the boiler is very low. On basis of many verification tests of poly-generation technology at $1 \mathrm{MW}$ pilot plant, a $12 \mathrm{MW}$ demonstration project, designed by Zhejiang University in cooperation with the Huainan Mining (Group) Co., Ltd. had been erected and operated successfully from August 2007. Many tests had been conducted at this system. Results show that it could attain stable and continuous operation and produced not only high yield tar and high quality gas, but also heat and power.

\section{Application Prospect}

Coal pyrolysis and combustion poly-generation system converted coal into gas, tar, electricity and heat. Gas can be converted into natural gas or chemical product and tar was also converted into liquid fuel by hydro-refine process. Steam can be used for power generation, heat supply and refrigeration. What's more, N-containing and S-containing pollutants in fuel gas and flue gas were recovered to produce yields of sulfuric acid and calcium nitrite respectively, slag was refined to obtain precious metals and then used as construction materials. In general, coal poly-generation achieved comprehensive utilization of coal resource and nearly zero discharge of pollutants. The application prospect of poly-generation system was presented in Figure 2. 


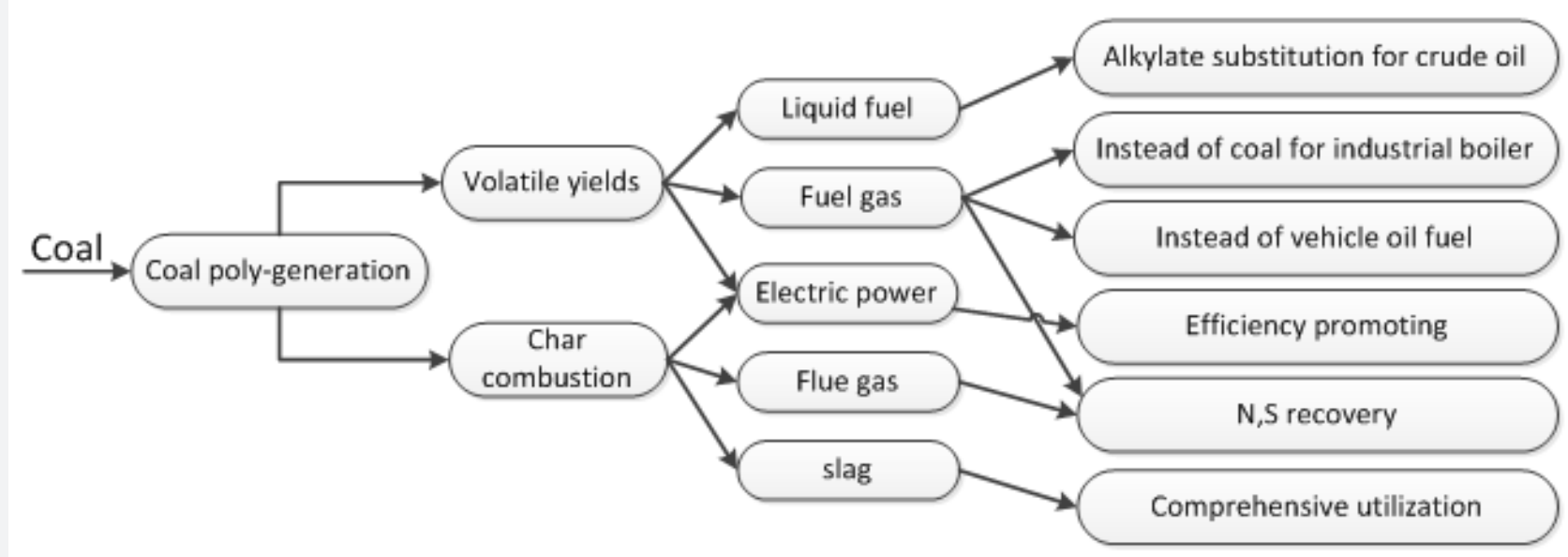

Figure 2: Application prospect of the new poly-generation system.

The total capacity of thermal power unit in China attained $765 \mathrm{GW}$, which consumed about 1.8 billion tons coal for power generation in 2011 . The volatile of total 1.8 billion tons coalis equal to natural gas of 271.3 billion cubic meters of which scale was 23 times larger than that of the West to East Pipeline Project or crude oil of 0.22 billion tons (the quantity of China oil imported was 0.25 billion tons in 2011). The yield of all coal ash will achieve about 0.45 billion tons and can produce1.1 billion tons cements with $32.5 \mathrm{MPa}$ strength grade (the amount of cement achieving 2.06 billion tons in 2011) or generate Al203 product of 90 million tons (the number of electrolytic aluminium was 18.06 million tons in 2011) and 20 million tons ferric oxide. The recovery of sulfuric acid will reach 40 million tons (apparent sulfur consumption of China was 13.52 million tons) and about 30 million tons products of calcium nitrite or ammonium nitrate.

Now the industrial boiler is a big problem as its huge number, low efficiency and high pollution. If all coal fired industrial boiler would be substituted for fuel gas from the poly-generation system, it could increase efficiency of industrial boiler from $65 \%$ to $85 \%$, which will save 100 million tons coal every year, and lower the emission of SO2, NOX, PM2.5 and $\mathrm{CO}_{2}$ greatly.

In summary, the poly-generation system can supply multienergy like gas, oil, heat and electricity and will be strategically important for energy-saving and emission reduction. So it is a promising clean and high efficiency coal technology to electric power generation, replacement of oil and gas resources and circular economy in China.

\section{Conclusion}

A new coal pyrolysis and combustion poly-generation system combined coal combustion and pyrolysis has been developed for clean and high efficient utilization of coal. Through pyrolysis, coal got converted into gas, tar and semicoke. The system can realize coal multi-product generation and has a great potential to increase coal utilization value.

\section{Acknowledgement}

This work is supported by National Key R\&D Program of China (2017YFB0602800), International Cooperation Project (2011DFR60190.

\section{References}

1. Paterson N (1997) Fuel behaviour studies in the air-blown gasification cycle. Fuel 76(13): 1319-1325.

2. YH Zhu, Somasundaram S, Kemp JW (2010) Energy and energy analysis of gasifier-based coal-to-fuel systems. Journal of energy resources technology-transactions of the ASME 13(2): 8.

3. Qun Yi, Jie Feng, YingLi W (2012) Optimization and efficiency analysis of polygeneration system with coke-oven gas and coal gasified gas by Aspen Plus. Fuel 96: 131-140.

4. T Kreutz, Robert W, Consonni S, Chiesa P (2005) Co-production of hydrogen, electricity and $\mathrm{CO}_{2}$ from coal with commercially ready technology. Part B: Economic analysis. International Journal of Hydrogen Energy 30(7): 769-784.

5. Paolo Chiesa, T Kreutz, Robert W, Consonni S (2005) Co-production of hydrogen, electricity and $\mathrm{CO}_{2}$ from coal with commercially ready technology. Part A: Performance and emissions. International Journal of Hydrogen Energy 30(7): 747-767. 
(C) This work is licensed under Creative

(1) Commons Attribution 4.0 Licens

BY DOI: 10.19080/RAPSCI.2017.02.555595

\section{Your next submission with Juniper Publishers will reach you the below assets}

- Quality Editorial service

- Swift Peer Review

- Reprints availability

- E-prints Service

- Manuscript Podcast for convenient understanding

- Global attainment for your research

- Manuscript accessibility in different formats ( Pdf, E-pub, Full Text, Audio)

- Unceasing customer service

Track the below URL for one-step submission https://juniperpublishers.com/online-submission.php 